\title{
Chronic amphetamine treatment increases striatal calmodulin in rats
}

\author{
JILL M. ROBERTS-LEWIS ${ }^{1 * *}$, MICHAEL J. WELSH ${ }^{2}$ and MARGARET E. GNEGY ${ }^{3}$ \\ Departments of ${ }^{1}$ Psychology. ' Anatomy and Cell Biology, and ${ }^{3}$ Pharmacology, \\ The University of Michigan, Ann Arbor, MI 48109 (U.S.A.)
}

(Accepted 24 June 1986)

Key words: Amphetamine - Calcium — Calmodulin - Dopamine - Sensitization — Striatum - Radioimmunoassay

\begin{abstract}
A radioimmunoassay was developed to measure calmodulin in striatum from rats treated with one dose or repeated injections of amphetamine. Chronic, but not acute, amphetamine treatment resulted in a significant increase in total calmodulin levels in striatal homogenates. This effect may be linked to the behavioral sensitization which develops after chronic amphetamine treatments.
\end{abstract}

When rats are administered a single dose or repeated injections of amphetamine (AMPH), they exhibit a marked behavioral potentiation to subsequent challenges with AMPH which persists several weeks after the initial exposure to the drug ${ }^{14}$. This pharmacological sensitization is correlated with an increase in the amount of dopamine which is released from striatal tissue in vitro in response to AMPH infusion $^{9.13}$. The molecular events underlying these changes are unknown. The present study was designed to explore the possible involvement of the calcium binding protein, calmodulin (CaM), which affects a number of critical enzyme activities in the CNS, including calcium-dependent adenylate cyclase. phosphodiesterase, and protein kinase activities $^{10}$. This neuromodulator protein is particularly enriched in synaptic fractions of the brain, where it is associated with the nuclear matrix, cytosol, vesicles, and postsynaptic density ${ }^{10}$. CaM appears to be involved in the synthesis and release of many neurotransmitters, as well as other possible cell functions ${ }^{5}$. $\mathrm{CaM}$ is also abundant in striatum ${ }^{19}$, where it has a demonstrated role in modulating dopaminergic activity through the dopamine-sensitive adenylate cyclase system $^{6.7}$. Treatments which up- or down-regulate dopaminergic activity result in a redistribution of
$\mathrm{CaM}$ between membrane and soluble subcellular fractions ${ }^{6,7}$. Therefore, CaM may have an important role in the regulation of dopaminergic neurotransmission in the nigrostriatal pathway, and in the behavioral changes due to manipulations of this system. We report here that a regimen of AMPH which results in behavioral sensitization also produces a significant increase in CaM levels in striatal homogenates.

Polyclonal antibodies against CaM were prepared in a sheep that was first immunized with performic acid-oxidized $\mathrm{CaM}^{17}$, then boosted with injections of native protein, according to the procedure described in Dedman et $\mathrm{al}^{4}$. Upon bleeding, serum for the radioimmunoassay described below is obtained by allowing the blood to clot, followed by centrifugation at $6000 \mathrm{~g}$ for $20 \mathrm{~min}$ at $4{ }^{\circ} \mathrm{C}$. This serum is then stored at $-20^{\circ} \mathrm{C}$ until it is thawed and diluted for use in the assay. Calmodulin from rat testes was purified by the method of Dedman et $\mathrm{al}^{3}$, and was radio-iodinated, or used for the standards in the radioimmunoassay described below. Lyophilized parvalbumin was obtained from Sigma Chemical Company.

Female, Holtzman rats $(225-250 \mathrm{~g})$ were injected (i.p.) with either $2.5 \mathrm{mg} / \mathrm{kg} \mathrm{AMPH}$ or an equal volume of saline once daily for 5 days. Ten days after the

\footnotetext{
* Present address: Department of Pharmacology, The Medical College of Pennsylvania, E.P.P.I., 3200 Henry Avenue, Philadelphia, PA 19129. U.S.A.

Correspondence: M.E. Gnegy, Department of Pharmacology, University of Michigan Medical School, M6322 Medical Science Building 1. Ann Arbor, MI 48109, U.S.A.
} 
last injection, all animals received either AMPH (2.5 $\mathrm{mg} / \mathrm{kg}$ i.p.) or saline $30 \mathrm{~min}$ before decapitation, such that 4 treatment groups were formed: (1) chronic treatment with AMPH - challenge with AMPH; (2) AMPH-saline; (3) saline-AMPH; (4) saline-saline. After decapitation, striata were rapidly removed and homogenized in 12 vols. of ice-cold $125 \mathrm{mM}$ borate buffer ( $\mathrm{pH} \mathrm{8.4)} \mathrm{containing} 75 \mathrm{mM} \mathrm{NaCl}$ and $3 \mathrm{mM}$ EGTA (RIA buffer). Crude homogenate, soluble. and $27,000 \mathrm{~g}$ particulate fractions were prepared for radioimmunoassay as follows. Homogenate and particulate fractions were solubilized in $1 \%$ Lubrol PX. and all samples were boiled at $95^{\circ} \mathrm{C}$ for $5 \mathrm{~min}$ and cooled rapidly in a dry ice-methanol bath (about $5 \mathrm{~s}$ ). Each sample was diluted in RIA buffer to between 0.05 and $0.4 \mathrm{mg}$ protein/assay tube and equilibrated for approximately $24 \mathrm{~h}$ at $4{ }^{\circ} \mathrm{C}$ in plastic tubes containing $10,000 \mathrm{cpm}$ of purified $\left[{ }^{125} \mathrm{l}\right] \mathrm{CaM}$ (prepared by Bolton and Hunter radio-iodination. NEN Du Pont, about $2000 \mathrm{Ci} / \mathrm{mmol}$ ), a 1:20 final dilution of sheep serum containing anti-CaM antibody, sufficient to bind about $20 \%$ of the total radioactivity, and RIA buffer containing $20 \mu \mathrm{g} \mathrm{BSA} / \mathrm{ml}$ in a final assay volume of $500 \mu \mathrm{l}$. Antigen-antibody complex was precipitated by adding $1 \mathrm{ml}$ of a $20 \%$ polyethylene glycol $\left(M_{r}=8000\right)$ solution to each tube. Samples were then vortexed, centrifuged at $5000 \mathrm{~g}$ for $30 \mathrm{~min}$. and the supernatants were aspirated. Pellets were counted for $\left[{ }^{125} \mathrm{I}\right]$ in a Tracor Analytic gamma counter. Quantitation of CaM content in the striatal extracts was derived by using a standard curve of highly purified, unlabelled CaM between 0.1 and $10 \mu \mathrm{g}$. The $\mathrm{IC}_{50}$ for $\left[{ }^{125} \mathrm{I}\right] \mathrm{CaM}$ displacement was $650 \mathrm{ng}$. Two or three dilutions per sample were measured to ensure tissue linearity with the standard curve. Treatment effects were evaluated by an analysis of variance with planned comparisons (contrasts) between the 4 treatment groups. The method described here is basically a modification of previously described CaM radioimmunoassays $^{2.18}$, with the novel advantage of replacing protein $\mathrm{A}$ or second antibody procedures with a polyethylene glycol precipitation of antigen-antibody complex, thereby reducing time and reagent costs.

Parvalbumin did not displace tracer at any concentration between 0.1 and $100 \mu \mathrm{g}$. while increasing concentrations of crude brain extracts displaced tracer with a curve of the same slope as the CaM standard curve (Fig. 1).

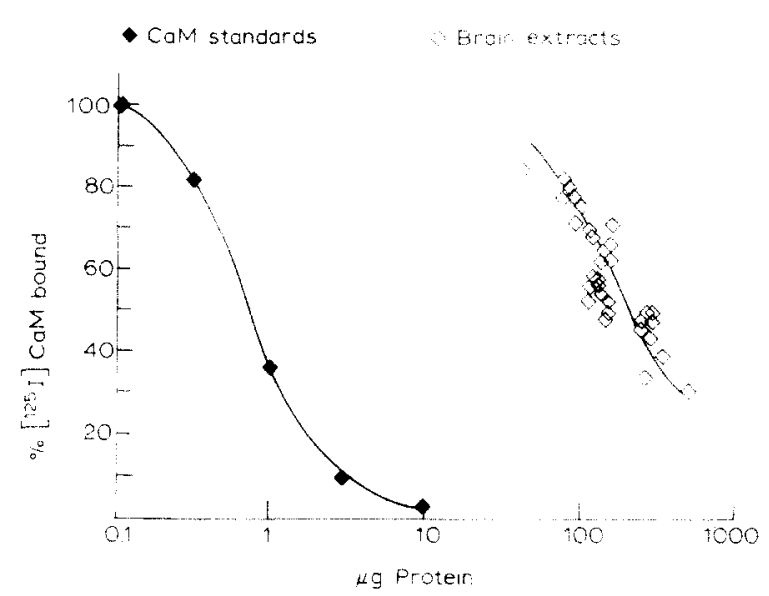

Fig. 1. [ [".5 I]Calmodulin displacement curves for purified. unlabelled calmodulin $(\bullet)$ and crude striatal extracts $(\circlearrowleft)$. The $\mathrm{IC}_{50}$ for purified calmodulin is $650 \mathrm{ng}$.

As seen in Fig. 2, total CaM levels in striatal homogenates from animals receiving chronic AMPH (group 1 or group 2) were significantly higher $(P<$ 0.001) than CaM levels in striatum from either acute AMPH (group 3) or saline controls (group 4). The membrane-bound pool of $\mathrm{CaM}$ that was not removed by EGTA-washing (EGTA-resistant) was not affected by AMPH treatments (Fíg. 2). This result indi-

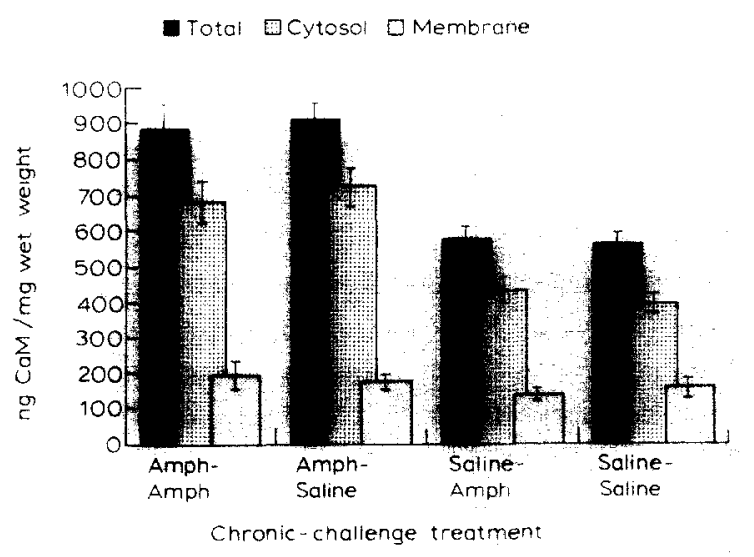

Fig. 2. Soluble (Cytosol), particulate (Membrane), and total calmodulin levels in striatum from rats which received 1 of the 4 chronic-challenge treatment regimens indicated above. Chronic treatments consisted of 5 injections of amphetamine (once daily for 5 days) followed by 9 days with no injections. Acute challenges with amphetamine were administered on the tenth day after the last injection, $30 \mathrm{~min}$ prior to decapitation. Crude particulate and soluble fractions were prepared from striata which were homogenized in a buffer containing $3 \mathrm{mM}$ EGTA, as described in the text. Data shown are the mean calmodulin levels \pm S.E.M. for 7-8 rats per group. 
cates that AMPH treatment is either increasing the $\mathrm{CaM}$ associated with a distinct, membrane-bound, labile (EGTA-sensitive) pool, or it is increasing CaM within the soluble pool. The possibility that a labile, membrane-bound pool of CaM may be selectively involved in the response to chronic alterations in nigrostriatal dopamine activity warrants further investigation. The functional significance of the non-labile (EGTA-resistant) pool also requires evaluation. There are reports of calcium-independent CaMbinding sites in brain ${ }^{1.8}$. However, it also appears that some of the calmodulin remaining in membranes after the EGTA wash is capable of stimulating adenylate cyclase activity in a calcium-dependent manner, since the addition of calcium to these membranes produces a small activation of adenylate $c y$ clase $^{6}$.

The observed increase in total CaM levels might indicate the de novo synthesis of new protein, or decreased degradation of existing CaM, or possibly the release of 'silent' $\mathrm{CaM}$ from a binding protein which prevented its detection by radioimmunoassay. Increasing CaM levels within a structure or compartment within a cell could decrease the calcium requirement for calcium-dependent enzymes located within that compartment, resulting in their activation. For example, presynaptic increases in striatal CaM might be expected to enhance dopamine synthesis through the calcium-dependent activation of tyrosine hydroxylase, or facilitate the release of dopamine in a manner which has been described for other neurotransmitter systems ${ }^{5}$. These events could, in turn, result in an increase in the amount of dopamine released by AMPH, which might be a critical feature in the development of behavioral sensitization to $\mathrm{AMPH}$, as suggested by Robinson and Becker $^{14}$. Furthermore, increases in striatal CaM may also selectively alter pre- or postsynaptic cAMP

1 Andreasen, T.J., Luetje. C.W., Heideman, W. and Storm, D.R., Purification of a novel calmodulin binding protein from bovine cerebral cortex membranes, Biochemistry, 22 (1983) 4615-4618.

2 Chafouleas, J.G., Dedman, J.R., Munjaal, R.P. and Means, A.R., Calmodulin. Development and application of a sensitive radioimmunoassay, J. Biol. Chem., 254 (1979) 10262-10267.

3 Dedman, J.R., Potter, J.D., Jackson, R.L., Johnson, J.D. and Means, A.R., Physiochemical properties of rat testis levels through the activation of calcium-dependent adenylate cyclase or phosphodiesterase $e^{6.7}$, either of which could modify the nigrostriatal signal which ultimately shapes behavioral responsivity to AMPH. We have shown that the striatal dopamine-sensitive adenylate cyclase system is modulated by doses of amphetamine which produce behavioral activation in rats $^{12}$, and there are also several studies which suggest that cAMP plays a role in the behavioral effects which are characteristic of dopamine agonists ${ }^{11.15}$. Although we have found no alteration in the sensitivity of striatal adenylate cyclase for dopamine or CaM in vitro after this chronic AMPH treatment regimen (unpublished findings), an alteration in adenylate cyclase activity due to in vivo changes in the compartmentation of CaM cannot be ruled out.

Other investigators have reported a decrease in dopamine $\mathrm{D}_{2}-\left[{ }^{3} \mathrm{H}\right]$ antagonist binding in striatal membranes from behaviorally sensitized rats after chronic $\mathrm{AMPH}^{14}$. In this context, it is interesting that Severson ${ }^{16}$ has noted a relationship between elevated striatal CaM levels and genetically decreased $\mathrm{D}_{2}$-dopamine receptor densities in mice. Together, these studies and the present findings suggest there could be a functional link between CaM and $\mathrm{D}_{2}$-dopamine receptors. Although the relationship between $\mathrm{CaM}$ and behavioral sensitization remains to be explored, the present results clearly reinforce the idea of a functional relationship between striatal calmodulin and nigrostriatal dopamine activity.

We would like to thank the University of Michigan Laboratory of Animal Medicine for the D-amphetamine sulfate used in these experiments, and Dr. George Brewer, Department of Human Genetics, for the use of his facilities for the iodination of calmodulin. This work was supported by Grant MH 36044-05.

$\mathrm{Ca}^{2+}$-dependent regulator protein of cyclic nucleotide phosphodiesterase. Relationship of $\mathrm{Ca}^{2+}-$ binding, conformational changes. and phosphodiesterase activity, J. Biol. Chem., 252 (1977) 8415-8422.

4 Dedman, J.R., Welsh, M.J. and Means. A.R., Ca ${ }^{2+}-\mathrm{de}-$ pendent regulator. Production and characterization of a monospecific antibody, J. Biol. Chem., 253 (1978) 7515-7521

5 DeLorenzo, R.J., Calmodulin in neurotransmitter relcase and synaptic function. Fed. Proc. Fed. Am. Soc. Exp. Biol., 
41 (1982) 2265-2272.

6 Gnegy, M.E., Relationship of calmodulin and dopaminergic activity in the striatum, Fed. Proc. Fed. Am. Soc. Exp. Biol., 41 (1982) 1173-1177.

7 Hanbauer, I., Pradham, S. and Yang, H.-Y.T., Role of calmodulin in dopaminergic transmission, Ann. N.Y. Acad. Sci., 356 (1980) 292-303.

8 Hooper, J.E. and Kelly, R.B., Calmodulin is tightly associated with synaptic vesicles independent of calcium, $J$. Biol. Chem., 259 (1984) 148-153.

9 Kolta, M.G., Shreve, P.. De Souza, V. and Uretsky, N.J., Time course of the development of the enhanced behavioral and biochemical responses to amphetamine after pretreatment with amphetamine. Neuropharmacology. 24 (1985) 823-829.

10 Manalan, A.S. and Klee, C.B., Calmodulin, Adv. Cyclic Nucleotide Res., 18 (1984) 227-278.

11 Miller, R.J. and Kelly, P.H., Dopamine-like effects of cholera toxin in the central nervous system, Nature (London), 255 (1975) 163-166.

12 Roberts-Lewis, J.M., Roseboom, P.H., Iwaniec, L.M. and Gnegy, M.E., Differential down-regulation of $D_{1}$-stimulated adenylate cyclase activity in rat forebrain after in vivo amphetamine treatments, $J$. Neurosci., in press.
13 Robinson, T.E. and Becker, J.B., Behavioral sensitization is accompanied by an enhancement in amphetamine-stimulated dopamine release from striatal tissue in vitro, Eur. $J$. Pharmacol., 85 (1982) 253-254.

14. Robinson, T.E. and Becker, J.B.. Enduring changes in brain and behavior produced by chronic amphetamine administration: a review and evaluation of animal models of psychosis, Brain Res. Rev., in press.

15 Satoh, H., Satoh, Y., Notsu, Y. and Honda, F. Adenosine $3^{\prime} .5^{\prime}$-monophosphate as a possible mediator of rotational behavior induced by dopaminergic receptor stimulation in rats lesioned unilaterally in the substantia nigra. Eur. J. Pharmacol, 39 (1976) 365-377.

16 Severson, J.A., Genotypic variation in striatal calmodulin content, Brain Research, 340 (1985) 79-86.

17 Van Eldik, L.J, and Watterson, D.M., Reproducible production and characterization of anti-calmodulin antisera. Ann. N.Y. Acad. Sci., 356 (1980) 437-438.

18 Wallace, R.W. and Cheung, W.Y., Calmodulin. Production of an antibody in rabbit and development of a radioimmunoassay, J. Biol. Chem., 254 (1979) 6564-6571.

19 Zhou, L.-W., Moyer, J.A., Muth, E.A., Clark, B., Palkovitz, M. and Weiss, B., Regional distribution of calmodulin activity in rat brain, J. Neurochem., 44 (1985) 1657-1662. 